Psychother Psychosom 2012;81:245-247

DOI: $10.1159 / 000332439$

\section{The Effect of Enhanced Depression Care on Anxiety Symptoms in Acute Coronary Syndrome Patients: Findings from the COPES Trial}

\author{
Ian M. Kronish ${ }^{\mathrm{a}}$, William F. Chaplin ${ }^{\mathrm{b}}$, Nina Rieckmann ${ }^{\mathrm{d}}$, \\ Matthew M. Burga, c, Karina W. Davidson ${ }^{\mathrm{a}}$ \\ ${ }^{a}$ Center for Behavioral Cardiovascular Health, Columbia \\ University Medical Center, and ${ }^{\mathrm{b}}$ Department of Psychology, \\ St. Johns University, New York, N.Y., and 'Section of \\ Cardiovascular Medicine, Yale University School of Medicine,

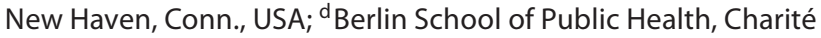 \\ University Medical Center, Berlin, Germany
}

Similar to depression, anxiety is common after acute coronary syndromes (ACS), and is an independent predictor of worse outcomes [1-3]. Yet, post-ACS psychological interventions have focused on treating depression. We previously reported that an enhanced depression care intervention involving patient preference for problem-solving therapy (PST), antidepressant medications, or both followed by stepped care according to treatment response was effective at reducing depressive symptoms after ACS with an effect size of $0.59 \mathrm{SD}$ [4]. We report here the independent effect of this intervention on anxiety.

The trial design is described elsewhere [5]. Briefly, hospitalized ACS patients who were persistently depressed (Beck Depression Inventory, BDI [6], score $\geq 10$ within 1 week of hospitalization and again 3 months later) were recruited from 5 US hospitals between 2005 and 2008 and randomized to enhanced depression care or to usual care on a 1:1 basis. Exclusion criteria were alcohol or drug dependency, dementia, psychosis or bipolar disorder, terminal illness, unavailability for follow-up, BDI score of $\geq 45$, or suicidality. The institutional review boards at all institutions approved the protocol, and all participants provided written informed consent.

Enhanced depression care consisted of patient preference for brief problem-focused psychotherapy (i.e., PST) and/or pharmacotherapy and stepped care in which symptom severity was reviewed every 8 weeks and treatment was augmented according to predetermined decision rules. Usual care was defined by the patient's treating physician(s).

Anxiety and depressive symptoms were assessed within 1 week of hospitalization, and at 3,5, 7, and 9 months. Anxiety was measured using the 7-item anxiety subscale of the Hospital Anxiety and Depression Scale (HADS-A) [7]. Depressive symptoms were assessed by the BDI [6]. Outcome assessors were blinded to group assignment.
Given the low number and apparent randomness of missing assessments (Little's MCAR $\chi^{2}=13.97, \mathrm{p}=0.12$ ), mixed effects regression was used to generate estimates of treatment effects on anxiety from month 3 to 9 and t test to assess the differential change in anxiety between groups (group $\times$ time interaction). Analyses were performed using SAS statistical software (version 9.2; SAS Institute Inc., Cary, N.C., USA).

The mean $( \pm S D)$ age of patients in the trial was $60.1 \pm 10.6$ years and 54\% were women. Enhanced and usual care patients were similar on demographic and baseline medical variables [4], on HADS-A score at baseline and 3 months (table 1), and in the percent with HADS-A in a range above normal (HADS-A >7; 61 vs. $60 \%$, respectively).

At 9 months, enhanced care patients showed a significant decrease in HADS-A compared to the 3-month pre-RCT assessment $(-2.51 ; 95 \%$ CI -3.77 to -1.26 ; $p<0.001)$, whereas there was no significant change in usual care patients $(0.13 ; 95 \% \mathrm{CI}-0.74$ to $1.01 ; \mathrm{p}=0.76)$, consistent with an effect size of enhanced care on anxiety of 0.53 (table 1). Change in HADS-A was moderately correlated with change in BDI (Pearson's $\mathrm{r}=0.44, \mathrm{p}<0.001$ ). Controlling for depression, the effect of enhanced care on anxiety was decreased by about 1 point, but remained significant (mean group difference $-1.40 ; 95 \% \mathrm{CI}-2.62$ to $-0.24 ; \mathrm{p}=0.02$ ). A subgroup analysis suggested a benefit of enhanced care on anxiety in women but not men (table 1).

These results demonstrate that enhanced depression care involving patient treatment preference of PST and/or antidepressant medications followed by stepped care has collateral benefits on anxiety in post-ACS patients. Symptoms of anxiety are common after ACS, can decrease treatment adherence $[8,9]$, lower quality of life [10], and contribute to worse cardiovascular prognosis [2]. Yet, similar to depression, anxiety is often not assessed after ACS and patients with elevated anxiety often go untreated [11]. Thus the current findings demonstrate one viable approach to improving care for anxious post-ACS patients.

The use of PST may have contributed to the collateral benefit of the intervention on anxiety. PST is a patient-directed as opposed to disease-focused therapy in which patients are taught how to systematically evaluate and address individual psychosocial problems of their choosing. Interestingly, over $60 \%$ of enhanced care patients initially chose PST over antidepressant medications [4].

Subgroup analysis showed an effect on anxiety for women but not men. Prior trials of enhanced depression care have been mixed with some finding gender effects in which men benefit more than women [12], and others not $[4,13]$. To our knowledge, no prior trials have reported an interaction between gender and anxiety treatment in cardiovascular populations. If our finding is replicated, then future anxiety interventions may be more successful if tailored according to gender.

\section{KARGER}

Fax +41 613061234

E-Mail karger@karger.ch

www.karger.com
C) 2012 S. Karger AG, Basel

0033-3190/12/0814-0245\$38.00/0

Accessible online at: www.karger.com/pps 
Table 1. Reduction in anxiety symptoms 0,3 and 9 months after acute coronary syndrome

\begin{tabular}{|c|c|c|c|c|}
\hline \multirow[t]{2}{*}{ Variable } & \multirow{2}{*}{$\begin{array}{l}\text { Usual care group } \\
(\mathrm{n}=77)\end{array}$} & \multirow{2}{*}{$\begin{array}{l}\text { Intervention group } \\
(\mathrm{n}=80)\end{array}$} & \multicolumn{2}{|l|}{ Intervention vs. usual care } \\
\hline & & & between-group difference & $p$ \\
\hline Anxiety score at 0 month & $7.53(6.41$ to 8.66$)$ & $7.68(6.57$ to 8.79$)$ & $-0.14(-1.72$ to 1.43$)$ & 0.86 \\
\hline Anxiety score at 3 months (pre-RCT assessment) & $8.29(7.27$ to 9.31$)$ & $8.87(7.97$ to 9.77$)$ & $-0.57(-1.92$ to 0.77$)$ & 0.40 \\
\hline Anxiety score at 9 months & $8.35(7.19$ to 9.51$)$ & $6.70(5.75$ to 7.64$)$ & $1.65(0.17$ to 3.13$)$ & 0.03 \\
\hline Change in anxiety score (3-9 months) - overall & $0.13(-0.74$ to 1.01$)$ & $-2.38(-3.29$ to -1.48$)$ & $-2.51(-3.77$ to 1.26$)$ & $<0.001$ \\
\hline $\begin{array}{l}\text { Change in anxiety score (3-9 months) - overall, adjusting for } \\
\text { depressive symptoms }\end{array}$ & $0.79(-0.04$ to 1.63$)$ & $-0.64(-1.54$ to 0.26$)$ & $-1.43(-2.62$ to -0.24$)$ & 0.02 \\
\hline Women only $(\mathrm{n}=84)$ & $1.33(0.10$ to 2.56$)$ & $-1.27(-2.61$ to 0.06$)$ & $-2.60(-4.34$ to -0.86$)$ & 0.004 \\
\hline Men only $(n=73)$ & $0.18(-0.92$ to 1.28$)$ & $0.11(-1.09$ to 1.30$)$ & $-0.07(-1.66$ to 1.51$)$ & 0.93 \\
\hline
\end{tabular}

The anxiety scores at 0, 3 and 9 months are presented as mean ( $95 \%$ confidence interval). The change scores (95\% confidence interval) for each group are parameter estimates for the dummy coded pre-post variable from the mixed effects regression models, and the between-group differences (95\% confidence interval) in change are the parameter estimates for the group $\times$ pre-post interaction from the mixed effects regression analysis. Anxiety was assessed using the HADS [7].

The secondary nature of the current analyses and sample selection (for depression vs. anxiety) limit interpretations that can be made, as does the use of HADS-A as a measure of anxiety in place of a diagnostic psychiatric interview. While an elevated HADS-A score has been associated with clinical diagnoses, anxiety disorders are heterogeneous and individual disorders may confer differing risks on post-ACS prognosis [14]. Nevertheless, elevated anxiety symptoms have been associated with a worse cardiac prognosis in prior studies [1]. Another limitation is that the comparison group was usual care rather than placebo/active control. Thus, we did not account for nonspecific effects of treatment on anxiety. Finally, 12 of the 80 patients randomized to treatment never received the intervention; this highlights the importance of considering the availability and acceptability of psychological interventions in post-ACS patients.

In conclusion, future interventions to reduce psychological distress after ACS should assess their effectiveness on both depression and anxiety symptoms. Those interventions with pleiotropic effects on both anxiety and depression may be best suited to not only improve quality of life in ACS survivors, but potentially, to reduce the risk of psychological distress on adverse cardiovascular outcomes. Future trials should consider whether to target depressed patients, alone, or to broaden enrollment criteria to include patients with depression and/or anxiety after ACS [15]. Although the intervention reduced anxiety symptoms compared to usual care, $42 \%$ of intervention participants had persistently elevated anxiety symptoms (HADS-A >7) at 9 months. Accordingly, post-ACS patients with combined anxiety and depressive symptoms may benefit from a sequential approach in which anxiety symptoms are monitored alongside depressive symptoms, and are targeted by alternating treatment strategies (psychotherapy and pharmacotherapy), depending on the individual history, course, and severity of the patients' symptoms and symptom profiles [16].

\section{Acknowledgements}

This work was supported by grants HC-25197, HL-088117, HL-76857, and HL-84034 from the National Institutes of Health (NIH), Bethesda, MD, and by grant Number UL1 RR024156 from the National Center for Research Resources (NCRR), a component of NIH and NIH Roadmap for Medical Research. In addition, Dr. Kronish was supported in part by 1K23HL098359 from the National Heart, Lung, and Blood Institute. The contents of this article are solely the responsibility of the authors and do not necessarily represent the official view of NCRR or NIH.

\section{Disclosure Statement}

The authors have no conflict of interest to declare.

\section{References}

$\checkmark 1$ Roest AM, Martens EJ, Denollet J, de Jonge P: Prognostic association of anxiety post myocardial infarction with mortality and new cardiac events: a meta-analysis. Psychosom Med 2010;72:563-569.

2 Frasure-Smith N, Lesperance F: Depression and anxiety as predictors of 2-year cardiac events in patients with stable coronary artery disease. Arch Gen Psychiatry 2008;65:62-71.

-3 Grace SL, Abbey SE, Irvine J, Shnek ZM, Stewart DE: Prospective examination of anxiety persistence and its relationship to cardiac symptoms and recurrent cardiac events. Psychother Psychosom 2004;73: 344-352.

4 Davidson KW, Rieckmann N, Clemow L, Schwartz JE, Shimbo D, Medina V, Albanese G, Kronish I, Hegel M, Burg MM: Enhanced depression care for patients with acute coronary syndrome and persistent depressive symptoms: coronary psychosocial evaluation studies randomized controlled trial. Arch Intern Med 2010;170:600-608.

5 Burg MM, Lespérance F, Rieckmann N, Clemow L, Skotzko C, Davidson KW: Treating persistent depressive symptoms in post-ACS patients: the project COPES phase-I randomized controlled trial. Contemp Clin Trials 2008;29:231-240.

-6 Beck AT, Ward CH, Mendelson M: An inventory for measuring depression. Arch Gen Psychiatry 1961;4:561-571.

7 Zigmond AS, Snaith RP: The hospital anxiety and depression scale. Acta Psychiatr Scand 1983;67:361-370.

$>8$ Benninghoven D, Kaduk A, Wiegand U, Specht T, Kunzendorf S, Jantschek G: Influence of anxiety on the course of heart disease after acute myocardial infarction - risk factor or protective function? Psychother Psychosom 2006;75:56-61.

$\checkmark 9$ Kuhl EA, Fauerbach JA, Bush DE, Ziegelstein RC: Relation of anxiety and adherence to risk-reducing recommendations following myocardial infarction. Am J Cardiol 2009;103:1629-1634. 
10 Dickens CM, McGowan L, Percival C, Tomenson B, Cotter L, Heagerty A, Creed FH: Contribution of depression and anxiety to impaired health-related quality of life following first myocardial infarction. Br J Psychiatry 2006;189:367-372.

11 Huffman JC, Smith FA, Blais MA, Beiser ME, Januzzi JL, Fricchione GL: Recognition and treatment of depression and anxiety in patients with acute myocardial infarction. Am J Cardiol 2006;98:319-324.

12 Rollman BL, Belnap BH, LeMenager MS, Mazumdar S, Houck PR, Counihan PJ, Kapoor WN, Schulberg HC, Reynolds CF 3rd: Telephone-delivered collaborative care for treating post-CABG depression: a randomized controlled trial. JAMA 2009;302:2095-2103.

13 Schneiderman N, Saab PG, Catellier DJ, Powell LH, DeBusk RF, Williams RB, Carney RM, Raczynski JM, Cowan MJ, Berkman LF, Kaufmann PG: Psychosocial treatment within sex by ethnicity subgroups in the enhancing recovery in coronary heart disease clinical trial. Psychosom Med 2004;66:475-483.
14 Parker G, Hyett M, Hadzi-Pavlovic D, Brotchie H, Walsh W: GAD is good? Generalized anxiety disorder predicts a superior five-year outcome following an acute coronary syndrome. Psychiatry Res 2011;188:383-389.

15 Huffman JC, Mastromauro CA, Sowden G, Fricchione GL, Healy BC, Januzzi JL: Impact of a depression care management program for hospitalized cardiac patients. Circ Cardiovasc Qual Outcomes 2011;4: 198-205.

16 Fava GA, Tomba E: New modalities of assessment and treatment planning in depression: the sequential approach. CNS Drugs 2010;24:453-465.

Ian M. Kronish, MD, MPH

Center for Behavioral Cardiovascular Health

Columbia University Medical Center, PH9-311

622 W168th Street, New York, NY 10032 (USA)

Tel. +1 212342 1335, E-Mail ik2293@ columbia.edu 